\title{
Quantifying natural disturbances using a large-scale dendrochronological reconstruction to guide forest management
}

\author{
Vojtěch Čada (D) ${ }^{1,12}$ Volodymyr Trotsiuk (D) ${ }^{1,2}$ Pavel Janda, ${ }^{1}$ Martin Mikolášs̆, ${ }^{1,3}$ Radek Bače, ${ }^{1}$ \\ Thomas A. Nagel,${ }^{1,4}$ Robert C. Morrissey, ${ }^{1}$ Alan J. Tepley (D) ${ }^{5}$ Ondřej Vostarek $\left(i D,{ }^{1}\right.$ Krešimir Begović, ${ }^{1}$

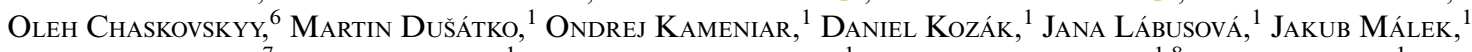 \\ Peter Meyer, ${ }^{7}$ Joseph L. Pettit, ${ }^{1}$ Jonathan S. Schurman, ${ }^{1}$ Kristýna Svobodová, ${ }^{1,8}$ Michal Synek, ${ }^{1}$ \\ Marius Teodosiu, ${ }^{9,10}$ Karol Ujházy, ${ }^{11}$ and Miroslav Svoboda ${ }^{1}$ \\ ${ }^{1}$ Department of Forest Ecology, Faculty of Forestry and Wood Sciences, Czech University of Life Sciences Prague, Kamýcká 129, \\ Praha 6 - Suchdol, Prague 16500 Czech Republic \\ ${ }^{2}$ Swiss Federal Institute for Forest, Snow and Landscape Research WSL, Zürcherstrasse 111, Birmensdorf CH-8903 Switzerland \\ ${ }^{3}$ PRALES, Odtrnovie 563, Rosina SK-01322 Slovakia \\ ${ }^{4}$ Department of Forestry and Renewable Forest Resources, University of Ljubljana, Večna pot 83, Ljubljana 1000 Slovenia \\ ${ }^{5}$ Division of Biological Sciences, W.A. Franke College of Forestry \& Conservation, University of Montana, Missoula, Montana 59812 \\ USA \\ ${ }^{6}$ Faculty of Forestry, Ukrainian National Forestry University, Gen. Chuprynka 103, Lviv 79057 Ukraine \\ ${ }^{7}$ North West German Forest Research Institute, Grätzelstrasse 2, Göttingen D-37079 Germany \\ ${ }^{8}$ Faculty of Environmental Sciences, Czech University of Life Sciences Prague, Kamýcká 129, Praha 6 - Suchdol, Prague 16500 Czech \\ Republic \\ 9 “Marin Drăcea” National Research-Development Institute in Forestry, Station Câmpulung Moldovenesc, Calea Bucovinei $73 b$, \\ Câmpulung Moldovenesc, Suceava 725100 Romania \\ ${ }^{10}$ Ștefan cel Mare University of Suceava, Universităţii 13, Suceava 720229 Romania \\ ${ }^{11}$ Technical University in Zvolen, T.G. Masaryka 24, Zvolen 96053 Slovakia
}

Citation: Čada, V., V. Trotsiuk, P. Janda, M. Mikoláš, R. Bače, T. A. Nagel, R. C. Morrissey, A. J. Tepley, O. Vostarek, K. Begović, O. Chaskovskyy, M. Dušátko, O. Kameniar, D. Kozák, J. Lábusová, J. Málek, P. Meyer, J. L. Pettit, J. S. Schurman, K. Svobodová, M. Synek, M. Teodosiu, K. Ujházy, and M. Svoboda. 2020. Quantifying natural disturbances using a large-scale dendrochronological reconstruction to guide forest management. Ecological Applications 30(8):e02189. 10.1002/eap.2189

Abstract. Estimates of historical disturbance patterns are essential to guide forest management aimed at ensuring the sustainability of ecosystem functions and biodiversity. However, quantitative estimates of various disturbance characteristics required in management applications are rare in longer-term historical studies. Thus, our objectives were to (1) quantify past disturbance severity, patch size, and stand proportion disturbed and (2) test for temporal and subregional differences in these characteristics. We developed a comprehensive dendrochronological method to evaluate an approximately two-century-long disturbance record in the remaining Central and Eastern European primary mountain spruce forests, where wind and bark beetles are the predominant disturbance agents. We used an unprecedented large-scale nested design data set of 541 plots located within 44 stands and 6 subregions. To quantify individual disturbance events, we used tree-ring proxies, which were aggregated at plot and stand levels by smoothing and detecting peaks in their distributions. The spatial aggregation of disturbance events was used to estimate patch sizes. Data exhibited continuous gradients from low- to high-severity and small- to large-size disturbance events. In addition to the importance of small disturbance events, moderate-scale (25-75\% of the stand disturbed, $>10$ ha patch size) and moderate-severity (25-75\% of canopy disturbed) events were also common. Moderate disturbances represented more than $50 \%$ of the total disturbed area and their rotation periods ranged from one to several hundred years, which is within the lifespan of local tree species. Disturbance severities differed among subregions, whereas the stand proportion disturbed varied significantly over time. This indicates partially independent variations among disturbance characteristics. Our quantitative estimates of disturbance severity, patch size, stand proportion disturbed, and associated rotation periods provide rigorous baseline data for future ecological research, decisions within biodiversity conservation, and silviculture intended to maintain native biodiversity and ecosystem functions. These results highlight a need for sufficiently large and adequately connected networks of strict reserves, more complex silvicultural treatments

Manuscript received 18 November 2019; revised 8 February 2020; accepted 17 March 2020. Corresponding Editor: Carolyn H. Sieg.

${ }^{12}$ E-mail: cada@fld.czu.cz 
that emulate the natural disturbance spectrum in harvest rotation times, sizes, and intensities, and higher levels of tree and structural legacy retention.

Key words: disturbance-based forestry; ecosystem management; intermediate disturbances; Ips typographus; mixed-severity disturbance regime; mortality; nonequilibrium forest dynamics; old-growth forests; Picea abies; primary forests; retention forestry; windthrows.

\section{INTRODUCTION}

Inappropriate forest management that alters forest structures, compositions, or functions as a result of the replacement or alteration of historical disturbance patterns cause serious ecological harm, such as the loss of biodiversity or soil degradation (Achat et al. 2015, Mikolás et al. 2017b). As characterized in the concept of the "historical range of variability" (Keane et al. 2009), specific variations of past disturbances were the primary drivers of forest conditions that native forest species had adapted to over long periods of time, and they are likely to benefit from similar conditions in the future (Drapeau et al. 2016, Mikoláš et al. 2017a, Betts et al. 2019). Using the historical range of variability (e.g., by emulating natural disturbances) to guide forest management will help sustain forest ecosystem structures, composition, and functions (Seymour et al. 2002, Long 2009, Kulakowski et al. 2017). Natural disturbance characteristics can provide a guide to key management decisions, such as harvest rotation times, size, and intensity, that can be linked to natural disturbance frequency, patch size, and severity, respectively (Seymour et al. 2002, Keane et al. 2009). Natural disturbance patterns can also provide answers as to what, how much, and where forest structures should be left as a part of retention forestry approaches (Fedrowitz et al. 2014, Mori and Kitagawa 2014).

Dendrochronological reconstructions are among the most useful methods to provide long, spatially explicit records of disturbance characteristics (Lorimer and Frelich 1989, Svoboda et al. 2014, Schurman et al. 2018). Estimates of disturbance frequency are commonly emphasized in dendrochronological approaches. However, to the detriment of management applicability of dendrochronological results, quantitative estimates of multiple disturbance characteristics have rarely been developed (Keane et al. 2009), likely due to the temporal imprecision (e.g., delayed response of tree growth to disturbance or false positive reactions), complexity, or insufficient spatial coverage of the resulting records. As an example, long-term records of disturbance patch sizes are unavailable, despite being of extreme interest as a template for harvest size (a key attribute of forest management policies) or as a feature influencing landscape fluctuations and beta diversity (Lehnert et al. 2013, Drapeau et al. 2016). Here, we attempt to develop and apply a comprehensive quantitative method to estimate past disturbance characteristics (disturbance severity, patch size, and stand proportion disturbed) that can be directly used to develop sustainable forest management planning and policy.
Studies analyzing disturbance characteristics have mostly focused either on small, low-severity disturbance events, which cause the mortality of individual or small groups of trees and create gap-scale openings, or large, high-severity, catastrophic events, which kill nearly all the mature trees across large areas (Seymour et al. 2002). This could be partly because small events are frequent and readily visible in contemporary forest structures, while catastrophic events are often highlighted due to their extensive impact. More recently, moderate-scale and moderate-severity (also referred to as intermediate severity) disturbances are receiving increasing attention (e.g., see Stueve et al. 2011, Nagel et al. 2017, Meigs and Keeton 2018 and their reference lists); these events cause a peak in mortality over larger areas, but a substantial number of surviving mature trees are typically retained. Several analyses of moderate disturbance impacts have suggested that the cumulative sizes of these events may affect larger areas than catastrophic events, and they typically have a stronger influence on forest structure and composition than small, more frequent disturbances (Stueve et al. 2011, Nagel et al. 2017, Meigs and Keeton 2018). These studies also propose that the rotation periods of moderate disturbances are likely shorter than the lifespan of the dominant tree species. However, few studies have compared the relative frequency of moderate disturbances to small and large events in large-scale and long-term landscape dynamics (Fraver et al. 2009, Nagel et al. 2017). We explore this comparison to determine if moderate disturbances were more common and more important drivers of forests than is typically recognized, which is also central for forest management considerations.

Currently, there are no management guidelines based on natural forest disturbance dynamics for production forests in the mountains of Central and Eastern Europe (Kraus and Krumm 2013). These forests are dominated by Norway spruce (Picea abies), and they are managed primarily by even-aged methods using either shelterwood regeneration or regeneration on clearcuts (Cardellini et al. 2018). Harvest areas typically range between 1 and 3 ha in size, and they are managed on a rotation period between 80 and 120 yr (average 100 yr; Cardellini et al. 2018). Increasing recognition of the environmental and production losses caused by even-aged methods has led to the promotion of single- or group-selection management systems because these approaches are perceived as "closer-to-nature" under the philosophy of continuous cover management (Kraus and Krumm 2013, Brang et al. 2014). Although these approaches seek to produce conditions similar to natural forests, no studies have 
compared the sizes, frequencies, and intensities of management treatments vs. the characteristics of natural disturbances. We believe that quantitative recommendations are best suited for direct implementation into management and policy. In particular, values of disturbance characteristics around the upper end of the size-severity continuum are helpful to set limits (e.g., maximum sizes or severities) for management treatment regulations.

Recent natural disturbances in Central and Eastern European mountain spruce forests have caused extensive mortality across large areas in a few landscapes, while other regions have been subject to more localized smallor moderate-scale events (Senf and Seidl 2018). Likewise, plot- and stand-level dendrochronological reconstructions suggest that mixed-severity disturbance regimes with wide variation of low to high disturbance severities historically operated in mountain spruce forests (Svoboda et al. 2014, Trotsiuk et al. 2014, Čada et al. 2016). The prevailing disturbance agents are windstorms and bark beetle (Ips typhographus) outbreaks (Čada et al. 2016, Senf and Seidl 2018), although beetle disturbances are often triggered by windthrow events and local weather conditions, particularly droughts. At low population densities, beetles breed in fresh windthrown, weakened, or injured spruce trees that can cause beetle population size increases as this material accumulates (Wermelinger 2004, Marini et al. 2017). As the population size approaches the outbreak phase, the beetles will colonize and kill healthy, mature trees. These relationships enable high wind speeds and droughts to synchronize natural disturbances in mountain spruce forests, but these events are still spatially diverse and patchy, likely because mortality is also influenced by tree and stand sensitivity (predominantly increasing with tree size and age; Senf and Seidl 2018). Such a complex combination of disturbance sizes and severities seems to be a common characteristic of temperate forests predominantly driven by wind and insect disturbances (Fraver et al. 2009, Stueve et al. 2011). Therefore, European mountain spruce forests are representative of other forest types driven by wind and insect disturbances, and they provide a valuable test bed for quantifying various characteristics of past disturbance events using the methodological tools employed in this study.

Our objective was to quantify multiple characteristics of past disturbances, including the severity, patch size, and stand proportion disturbed, across an unprecedentedly large-scale nested design plot network in the remaining primary mountain spruce forests of Central and Eastern Europe. Building on long-tested dendroecological methods, we developed a comprehensive approach to quantify key disturbance characteristics. In addition, we tested for potential temporal and subregional differences in disturbance characteristics to understand the confidence range of our estimates. Our results provide valuable insight into the importance of moderate-scale and moderate-severity disturbances within a spectrum of natural events. Finally, we discuss how these results can be translated into management practices within the study region.

\section{Methods}

\section{Study forests}

We used a plot network established in the remaining primary mountain spruce forests of Central and Eastern Europe (remoteforests.org 2020; Schurman et al. 2018). Data were compiled from published regional studies across a large geographical gradient covering the Carpathian Mountains of southern and northern Romania (Svoboda et al. 2014), Ukraine (Trotsiuk et al. 2014), southern and northern Slovakia (Janda et al. 2017), the Bohemian Forest in the Czech Republic (Čada et al. 2016), and the Harz Mountains in Germany (Meyer et al. 2017; Fig. 1). Stands with no evidence of direct human influence, such as logging or livestock grazing, were selected with the help of local experts or primary forest inventories (Mikoláš et al. 2019). In stands of the Bohemian Forest, the prevailing influence of natural disturbances was evident by the significant association of reconstructed events and windstorm and bark beetle (Ips typographus) outbreak events in historical records (see Čada et al. 2016 for more details about possible human influence in these stands).

Norway spruce accounted for $97 \%$ of total tree basal area in our study forests with minor and regionally variable components of Pinus cembra, Sorbus aucuparia, and Abies alba, among several other less common species. The ground vegetation layers were dominated by Calamagrostis villosa, Vaccinium myrtillus, Avenella flexuosa, Athyrium distentifolium, and Luzula sylvatica. Tree density varied between 0 and 1,620 trees/ha (median: 430), and the live tree basal area ranged from 0 to $105 \mathrm{~m}^{2} /$ ha (median: 46). Lying deadwood volume ranged from 1 to $478 \mathrm{~m}^{3} / \mathrm{ha}$ (median: 105). Detailed distributions of selected structural parameters are presented in Appendix S1: Fig. S1.

Our study forests occupy relatively high altitudes ranging from 1,150 to $1,700 \mathrm{~m}$ above sea level near the alpine zone. Mean annual temperature varies between $1.5^{\circ} \mathrm{C}$ and $4^{\circ} \mathrm{C}$, with mean growing season (May-October) temperature ranges of $7.5-10^{\circ} \mathrm{C}$, and an annual precipitation of about $800-2,000 \mathrm{~mm}$ (data available online). ${ }^{13}$ Bedrock and soils are variable throughout the range, with Podzols being the predominant soil type, but with Cambisols present at lower elevations and Leptosols on stony exposed sites (Valtera et al. 2013).

\section{Data collection}

We used a hierarchical sample design of 541 plots nested within 44 stands (4-63 plots/stand; median: 11) nested within six subregions (4-13 stands/subregion; median: 6). The "West" subregion was comprised of the Harz and Bohemian Forest mountain ranges to avoid

\footnotetext{
${ }^{13}$ www.worldclim.org
} 


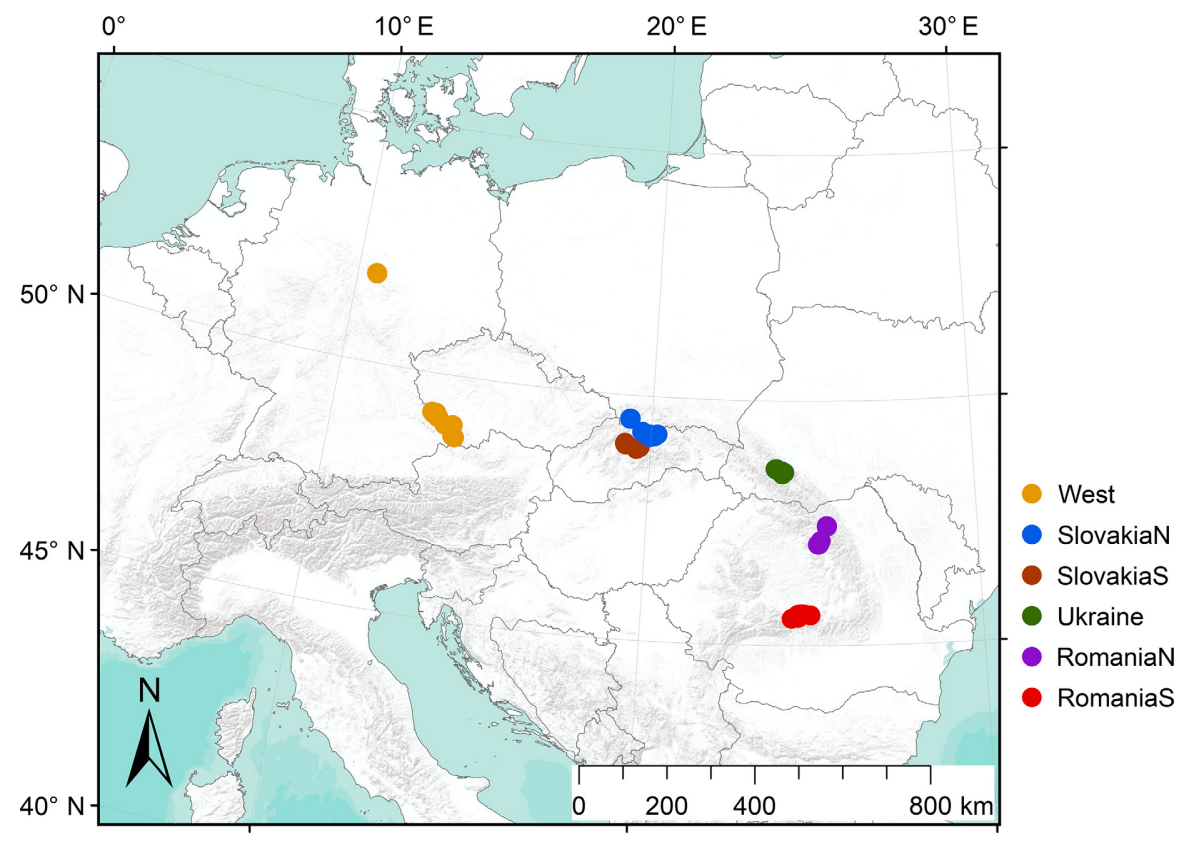

FIG. 1. Location of the study area of the remaining primary mountain Norway spruce forests spanning a large geographical gradient in Central and Eastern Europe. We distinguished six subregions within the study area containing 44 stands in total. Basemap service layers from ESRI, NOAA, and USGS are also displayed.

any subregion with a single stand (Fig. 1). Stand sizes ranged from 8 to 154 ha (median: 50 ) with a median density of one plot per 4.5 ha (range: one plot per $2.1-$ 9.8 ha). Stands were defined as a compact area, within which the plots were regularly distributed with similar density between stands. To accomplish that, we subdivided seven stands that were fragmented in their original studies, and we excluded 35 plots from the original database to homogenize plot densities among stands. Circular plots of $1,000 \mathrm{~m}^{2}$ (or $500 \mathrm{~m}^{2}$ in some dense homogeneous plots of northern Romania) were placed randomly within a regular grid covering the stand area.

Within each plot, we recorded the species and diameter of all living trees $>10 \mathrm{~cm}$ in diameter, and we measured the horizontal crown area of five trees. We extracted an increment core $1 \mathrm{~m}$ above the ground from 25 randomly selected non-suppressed trees (i.e., a tree that is exposed to direct sunlight and not overtopped by any neighboring trees) on each plot; in some cases, such as the dense homogeneous plots in northern Romania, only $15-20$ trees were sampled. In total, about 13,500 cores were processed using standard dendrochronological techniques, and ring-width series were measured and crossdated using a LINTAB sliding table and TsapWin software (RINNTECH, Heidelberg, Germany). Mean within-stand correlation between the individual raw ring-width series was 0.22 (range 0.09-0.42). Current crown areas of the cored trees were modelled using the relationships between crown area and diameter separately for each combination of species and subregion (Appendix S1: Table S1).

\section{Disturbance proxy evidence in tree-growth series}

Dendrochronological methods for evaluating past disturbance events rely on proxy evidence of disturbances recorded in the tree-ring series of trees that survived or were newly recruited after the disturbance events. We build on the method originally published by Lorimer and Frelich (1989), which relies on indirect proxy evidence (i.e., synchronous rapid early growth rates and growth releases) that is particularly useful in systems driven, for example, by wind, barkbeetle, or high-severity disturbances generally, where no clear direct evidence is available. However, we believe this approach is useful across a range of forests because in addition to the detection of disturbance events it also allows for the estimation of disturbance severity (see below).

Two types of radial growth patterns were assumed to indicate past disturbance: (1) release from suppression, characterized by an abrupt, large, and sustained growth increase, suggests a response to the mortality of surrounding trees, and (2) gap origin, characterized by rapid early growth rates, suggests the recruitment of a tree in open conditions after disturbance (Lorimer and Frelich 1989). A tree was determined to be a gap origin tree if the mean ring width of the fifth to fifteenth ring from the pith exceeded the early growth rate threshold, as previously defined by comparing early growth rates in young trees sampled in gaps vs. those growing under a forest canopy (Appendix S1: Table S2; Svoboda et al. 2014, Trotsiuk et al. 2014, Janda et al. 2017). The year 
when the gap origin tree was recruited to coring height was used as proxy evidence of a disturbance event. The year of a release from suppression was determined to be proxy evidence of a disturbance using the absolute increase method (Fraver and White 2005). The release was a year in the growth-series when the difference between the following 10-yr mean and the preceding $10-y r$ mean peaked and exceeded a threshold value that was defined as 1.25 times the standard deviation using the growth differences (absolute increase values) in the whole data set. We excluded growth increases that lasted less than seven years by comparison of lagged and leaded 10-yr means with the original preceding and following $10-\mathrm{yr}$ means. We considered only releases that happened more than $20 \mathrm{yr}$ after potential rapid early growth rate, and before the tree reached the threshold diameter that we assumed indicated it was a released tree of the canopy. The threshold diameter was based on comparisons of tree diameters of currently suppressed vs. released trees. We allowed for multiple proxy evidences of disturbances within individual trees. All the thresholds used were species- and subregion specific (Appendix S1: Table S1). Of all the disturbance proxy evidence recorded, $44 \%$ were rapid early growth rates and $41 \%$ were releases from suppression; the remaining $15 \%$ were represented by trees that did not fulfil any of our criteria, and those trees were treated as gap origin trees because sampling included only trees already recruited to the canopy (Lorimer and Frelich 1989).

\section{Disturbance events and disturbance characteristics}

Disturbance signal based on indirect proxy evidence in tree-ring series can be obscured by temporal lags in tree growth responses to disturbance events, and additional variability in tree-ring series unrelated to disturbances that result in both false positive and false negative detections of disturbances (Trotsiuk et al. 2018). To contend with the temporal imprecision, traditional methods typically rely on decadal binning of the data and the construction of a plot-level disturbance chronology, thus representing a composite of all disturbance proxy evidence throughout the plot history (Lorimer and Frelich 1989). Decadal binning may falsely detect multiple disturbance events (instead of a single real event) if the proxy evidence is dispersed over two or more consecutive decades, which would also result in an underestimation of disturbance severity. We improved upon the traditional technique by smoothing the data continuously rather than binning, which allowed us to distinguish individual disturbance events and address signal obscurity and false detections (described in detail below). In general, the compilation of disturbance proxy evidence identified for each tree produced a plot-level record of disturbance events, which was used to interpret disturbance severities. The compilation of plot-level disturbance events provided a stand-level record of disturbance events to interpret patch sizes and stand proportions disturbed.

At each plot, we smoothed the years of all the disturbance proxy evidence, which were weighted using the trees' relative current crown areas (i.e., current crown area of a tree divided by the sum of current crown areas of all trees cored on the plot), using a running kernel density function (Appendix S1: Fig. S2, Data S1; Trotsiuk et al. 2018). Kernel density is a nonparametric method to estimate the probability density function of random variables (Duong 2007). For the moving 30-yr window, we calculated the density with a smoothing bandwidth equal to 5 . We used the $\mathrm{R}$ software for these analyses (R Core Team 2018). From the resulting curve, we estimated the years of individual disturbance events by extracting peak years before which the curve was increasing for at least $5 \mathrm{yr}$. We also required that the distance between two peaks was more than $10 \mathrm{yr}$. The severity of an individual disturbance event was estimated as the relative canopy area disturbed on the plot, as determined by summing the relative current crown areas of trees whose disturbance proxy evidence occurred within the 11-yr window around the peak. This calculation relies on the conventional assumption that most trees respond to disturbances within a decade of the event and that the sum of relative current crown areas of trees that indicate past disturbance is representative of the proportion of the plot previously disturbed (Lorimer and Frelich 1989). To avoid false positives that might reflect variation in tree growth that is unrelated to disturbances, we removed peaks with a disturbance severity below $10 \%$. The results should be interpreted carefully because the disturbance severity can vary by more than $10 \%$ due to methodological decisions in the dendrochronological reconstructions (Šamonil et al. 2015, Čada et al. 2016, Trotsiuk et al. 2018). We believe that our estimates are rather conservative in an attempt to avoid false positives in the data; thus, we suggest that the method is more sensitive to underestimation rather than overestimation of disturbance severities.

To determine the proportion of stands affected by each disturbance, we first grouped plot-level disturbance events at the stand level using a similar approach to the plot-level summaries (Appendix S1: Fig. S3, Data S1). All the disturbance years from the plot level were smoothed using a running kernel density with the same coefficients, and peaks were again extracted by the same method as applied at the plot level. The analysis was limited to the period between 1810 and 1990; prior to 1810, the sample size was generally low, and tree-ring data beyond 1990 are not representative because the minimum tree size in our data excludes more recent tree recruitment. At the beginning of the period, our sample size contained 2,452 trees $(18 \%)$, 328 plots $(61 \%)$ had trees representing at least $10 \%$ of the canopy, and 42 stands $(95 \%)$ had at least one available plot (see Appendix S1: Fig. S4 for trends in sample size). To account for the variable numbers of plots per stand, to avoid exclusion of 
rare events, and to increase the robustness of the standlevel disturbance event estimations, we conducted a bootstrapped analysis on random subsets of the plots within each stand. We randomly selected 10 plots and calculated kernel density and extracted peaks, and we repeated this procedure 1,000 times. We smoothed the resulting distributions of bootstrapped peaks by a running kernel density using an 11-yr window and bandwidth equal to 1 , and we then extracted all stand-level peaks (i.e., standlevel years of disturbance events) separated by at least 10 yr. Each plot-level event was associated with the nearest stand-level event because we assumed there were no remaining false positive detections of disturbance events in the plot-level data. The median difference between plot-level disturbance events and the stand-level peaks was two years, and $95 \%$ of the events were no more than $8 \mathrm{yr}$ apart. This analysis cannot distinguish a single disturbance event from two consecutive events happening within one or two decades, so we consider all such cases as a single event. The delayed tree reactions to the disturbance event by more than a decade could potentially cause a single disturbance event to be classified as two consecutive events.

We estimated the patch size of each stand-level disturbance event based on the spatial distribution of plots showing evidence of the event (Appendix S1: Fig. S5, Data S1). Stand polygons were divided into a set of smaller polygons with one polygon for each plot using Thiessen polygons in ArcGIS 10.5 (ESRI, Redlands, California, USA). Plot-level polygons were labelled by the stand-level disturbance year evidenced on the matching plot, neighboring polygons that shared the same disturbance year were merged into a single patch, and the total patch area was calculated. We limited the patch size represented by a single plot to a maximum of 4 ha, which is just below the minimal limit that we could distinguish based on our plot density (see above). In the patch size analysis, we assumed that the unsampled area between two neighboring plots with evidence of the same disturbance event was similarly affected by this event. Although this assumption is likely not valid in all cases, we believe the unbiased randomized plot distribution ensures that the positive and negative errors in patch size estimations tended to balance out. We expect that many disturbance patches had irregular shapes and spatially variable severity across affected areas; however, we were able to analyze only sizes of the areas disturbed with more than $10 \%$ severity with the available data. Using this approach, we estimated years of disturbances and their associated patch sizes for each stand. We analysed patch sizes only in stands larger than 20 ha, which limited the analysis to a total of 40 stands.

Variation in plot-level disturbance severities, standlevel proportion of plots disturbed, and patch sizes were expressed in rotation periods based on the number of events per length of the chronology. The beginning of each chronology was associated with the year of the first disturbance event and the end year of each chronology was 1990. Rotation period was defined as the inverse of the disturbance frequency. The estimate of rotation periods is useful for forest management (Keane et al. 2009) because it provides the average time interval between successive disturbance events and the average proportion of the landscape affected within a given time period (Fraver et al. 2009). For example, we found 1,368 plotlevel disturbance events in total, and the total length of all plot-level chronologies was $84,447 \mathrm{yr}$, thus the average rotation period for disturbances that remove more than $10 \%$ of the forest canopy (severity) was estimated to be $62 \mathrm{yr}(84,447 \mathrm{yr} / 1,368$ events). We calculated $95 \%$ confidence intervals of the rotation periods based on bootstrapping techniques using 1,000 random subsets of 50 plots or 20 stands, as appropriate.

\section{Statistical analyses}

Because the patch size estimation was based on several assumptions, as discussed above, we complemented this analysis with a statistically unbiased estimation of spatial autocorrelation of disturbance events using Moran's $I$ in the ncf package (Bjørnstad 2018) of the R software (R Core Team 2018). We used Moran's I to test for both the degree of spatial autocorrelation in disturbance events and how the scale of spatial autocorrelation varied over time. We tested for autocorrelation among years of disturbance events after excluding extreme values of disturbance years before 1740 and after 1990. Then we calculated Moran's $I$ in the 30-yr running time window to obtain a temporal trend of spatial autocorrelation. The disturbance severities within the 30 -yr window ( 0 was used in cases with no detected disturbance event within the window) were used as input data in this analysis. We used 50-m distance classes and 1,000 Monte Carlo permutations to test the significance of spatial associations. The intercept of the correlogram model was used as a measure of the distance threshold below which the disturbance events are spatially autocorrelated, and it was also used as a proxy for patch size radius.

We tested the effect of subregion and time on the disturbance characteristics using multivariate analysis of variance (MANOVA) in the R software (R Core Team 2018). The disturbance data were initially averaged for each combination of stand and disturbance year, and the time interval (1810-1990) was divided into six periods to be used as a factor variable in the models to account for potentially nonlinear temporal effects. The most parsimonious model was selected by comparing complex and less complex models using ANOVA. Multiple post-hoc comparisons between subregions and periods were performed using Tukey's HSD test.

\section{RESULTS}

In 541 permanent plots established across European primary mountain spruce forests, we identified 1,368 
disturbance events that ranged in severity from $10 \%$ to $100 \%$. Across the 40 stands larger than 20 ha, we identified 287 stand-level disturbance events (303 across all 44 stands), represented by 573 discrete patches (some of the events included more than one non-contiguous patch within the same stand). Stand-level events suggested a maximum patch size of more than 93 ha with as much as $100 \%$ of the stand disturbed. Median values (and 95\% ranges) for the disturbance severities were $18.7 \%$ (10.465.6), for the patch sizes 4 ha (1.8-28.1), and for the stand proportions disturbed $25.0 \%$ (6.1-77.3). The reconstructed disturbance events generally aligned with documented historic windstorms and bark-beetle outbreaks (see the regional studies for more details; Svoboda et al. 2014, Čada et al. 2016, Janda et al. 2017, Meyer et al. 2017).

The data revealed a continuous gradient from lowseverity, small-scale disturbance events to higher-severity, larger-scale events, and this gradient is intimately related to the rotation period (frequency; Fig. 2), which shows that lower-severity and smaller-scale events are increasingly more frequent. Disturbances that removed tens of percent of canopy over areas up to tens of hectares occurred within a period comparable to spruce lifespan, which ranges from 150 to $450 \mathrm{yr}$ (Appendix S1: Fig. S1). These events remove more than a single or small group of trees, but they also leave a significant portion of surviving trees. High-severity and large-scale events that would be expected to kill essentially all mature trees across the areas larger than 100 ha were rare. However, precise size estimates of the largest patches are probably limited by the sizes of our stands, which we expect based on the significant correlation of maximum disturbance patch sizes to stand sizes (Appendix S1: Fig. S6). The overall variation of patch sizes was likely adequately captured because we observed no correlation between all patch sizes and stand sizes.

Natural disturbance characteristics markedly differ from the prevailing management system of production forests in the region (Fig. 2). The harvesting of all trees on 1-3 ha with a rotation period of approximately $100 \mathrm{yr}$ (Cardellini et al. 2018) is well outside the confidence interval of the spectrum of natural disturbance characteristics (Fig. 2). The logging operations under the prevailing system have shorter rotation periods and their severities are extremely high, while the patch sizes and stand proportions disturbed tend to be relatively low compared to the natural disturbance spectrum.

The importance of moderate-severity, moderate-scale, disturbance events for landscape dynamics is highlighted by the proportion of the total disturbed area represented by these disturbance types (Fig. 2). Altogether, $48 \%$ of the disturbed area was disturbed at moderate severity ( $25-75 \%$ canopy removal), which is comparable to the $47 \%$ of the area disturbed by lower-severity events (10$25 \%$ canopy removal). The disturbance sizes were also predominantly of moderate scale. Patch sizes larger than 10 ha comprised $58 \%$ of the total disturbed area, and stand proportions disturbed between $25 \%$ and $75 \%$ were evident across $69 \%$ of the area. By contrast, small- and large-scale events represented just $22 \%$ and $9 \%$ of the area considering the stand proportions disturbed. The patchy and irregular nature of disturbance events was suggested by the higher prevalence of moderate events when evaluated using stand proportion disturbed in comparison to the evaluation using disturbance severity or patch size. As is common in documented windstorms and bark-beetle outbreaks (Ips typographus), our method depicts that individual disturbance events typically produced multiple discrete disturbed patches per stand, where disturbance severity varied among those patches. Thus, a disturbance event was more likely characterized within the moderate disturbance category when evaluated using the stand proportion disturbed at stand level, where all the discrete patches and plot-level disturbance severities were combined together.

Spatial autocorrelation analysis supported that the disturbance events were significantly spatially clustered

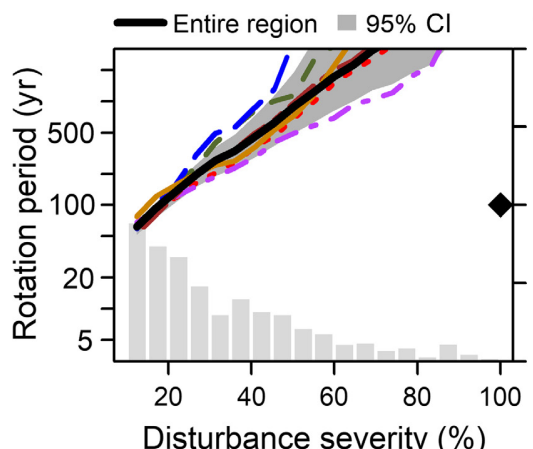

Disturbance severity (\%)
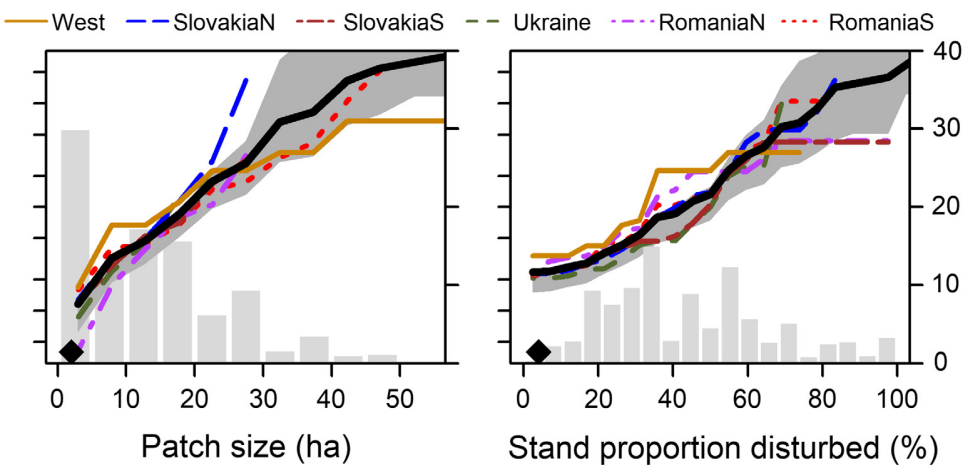

Stand proportion disturbed (\%)

FIG. 2. Rotation periods (lines) of disturbance severities, patch sizes, and stand proportion disturbed showing the average (idealized) interval between consecutive events of similar or higher disturbance class. Notice that rotation periods of disturbance severities (i.e., proportions of canopy area disturbed) are based on plot-level events, while periods of patch sizes and stand proportions disturbed are based on stands of an average size of approximately 50 ha. Gray bars represent a percentage of the area affected by the disturbance events of specific severity, patch size, or stand proportion disturbed class. The locally prevailing production forest management system of cutting all trees over the average area of 2 ha with an average rotation period of $100 \mathrm{yr}$ is shown for comparison (black squares). 
(Fig. 3a), which indicated that plots closer to one another exhibited more similar years of disturbance events. The spatial autocorrelation in disturbance years was significant up to a distance of $739 \mathrm{~m}$, which corresponds to a patch size of approximately 172 ha if the correlogram model intercept is considered to be representative of the patch radius. The synchrony of temporal trends in patch sizes as estimated by two different methods (i.e., for example, consistently peaking patch sizes around 1820, 1870, 1920; Fig. 3b) supports the robustness of our approach. The larger patch size resulting from spatial autocorrelation analysis could be explained by lower precision of this analysis. Similar years of disturbances does not necessarily mean the same events, as required in our patch-size analysis, and/or two close groups of plots attributed to the same event separated by plots with different events would be evaluated in the patch-size analysis as two different patches, but they could still contribute to the general autocorrelation (i.e., the entire area within a given autocorrelation distance was not necessarily disturbed in a given event). These results likely indicate interesting clustering and synchrony beyond the pattern of single disturbance events.

The MANOVA model (Fig. 4; Table 1) indicated that disturbance severity was significantly different among the subregions. In contrast, stand proportion disturbed varied significantly over time, as evident by the decline after 1930 (i.e., during the last two 30-yr periods). The effects of subregion on patch sizes, and the interaction of subregion and time period on stand proportion disturbed was only marginally significant. In general, our models explained only a small portion of the overall variation in disturbance characteristics, which were considerably broad across the entire data set. The most dissimilar subregions differed in disturbance severity by just $6.6 \%$, and stand proportion disturbed decreased by about $10 \%$ after about 1930 (Fig. 4). However, the overall ranges that contained $95 \%$ values of disturbance severity, patch size, and stand proportion disturbed values were as broad as $55 \%, 26$ ha, and $71 \%$, respectively. These subregional and temporal differences together with quantified overall variation provided a more robust and consistent picture of the confidence ranges of disturbance characteristics' rotation periods (Fig. 2), suggesting that a temporally and spatially nonequilibrium nature of forest dynamics is a typical attribute.

\section{Discussion}

We characterized, in detail, the disturbance regime of mountain spruce forests of Central and Eastern Europe using three complementary disturbance characteristics: disturbance severity, patch size, and stand proportion disturbed. Continuous gradients from low- to highseverity and small to large disturbance events were characteristic of these forests. This pattern probably represents well other temperate forests predominantly affected by wind and insect disturbances (Fraver et al. 2009, Stueve et al. 2011, Nagel et al. 2017). High structural complexity is evident across the landscape as a result of these disturbance characteristics, particularly in areas that experience more intensive events, which can produce spatially and temporally variable patterns of disturbance severity (Lehnert et al. 2013). Moderateseverity and moderate-scale events (tens of percent of canopy removed over tens of hectares) accounted for the largest portion of the total disturbed area compared to small- and large-scale events, despite the fact that they were less frequent than small-scale events.

\section{Methodological improvements}

Our approach improves upon traditional disturbance reconstruction methods by providing a framework to quantify distinct disturbance characteristics (disturbance severity, patch size, and stand proportion disturbed). By continuously smoothing the disturbance proxy data
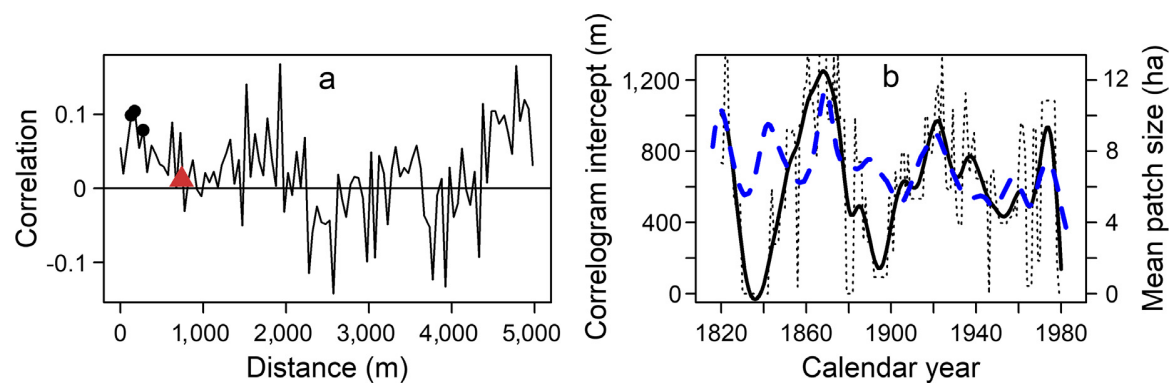

FIG. 3. (a) Moran's $I$ correlogram displaying trend of correlation of disturbance years in the plot neighborhood with increasing distance. Black dots represent significant $(P<0.001)$ correlations suggesting that there is an association between disturbance years of neighboring plots up to a distance of several hundred meters. The correlogram model intercept shown by brown triangle (739 $\mathrm{m}$ ) is used as a measure of distance up to which there is a spatial autocorrelation. (b) Temporal trend of Morans' I correlogram model intercepts (black dotted line) smoothed using a spline function (thick black line) in comparison to the trend of disturbance patch sizes also smoothed using a spline function (blue dashed line); the lines of independent measures of disturbance sizes show a similar trend with two peaks in late 19 th and early 20 th century and no clear long-term trend. 

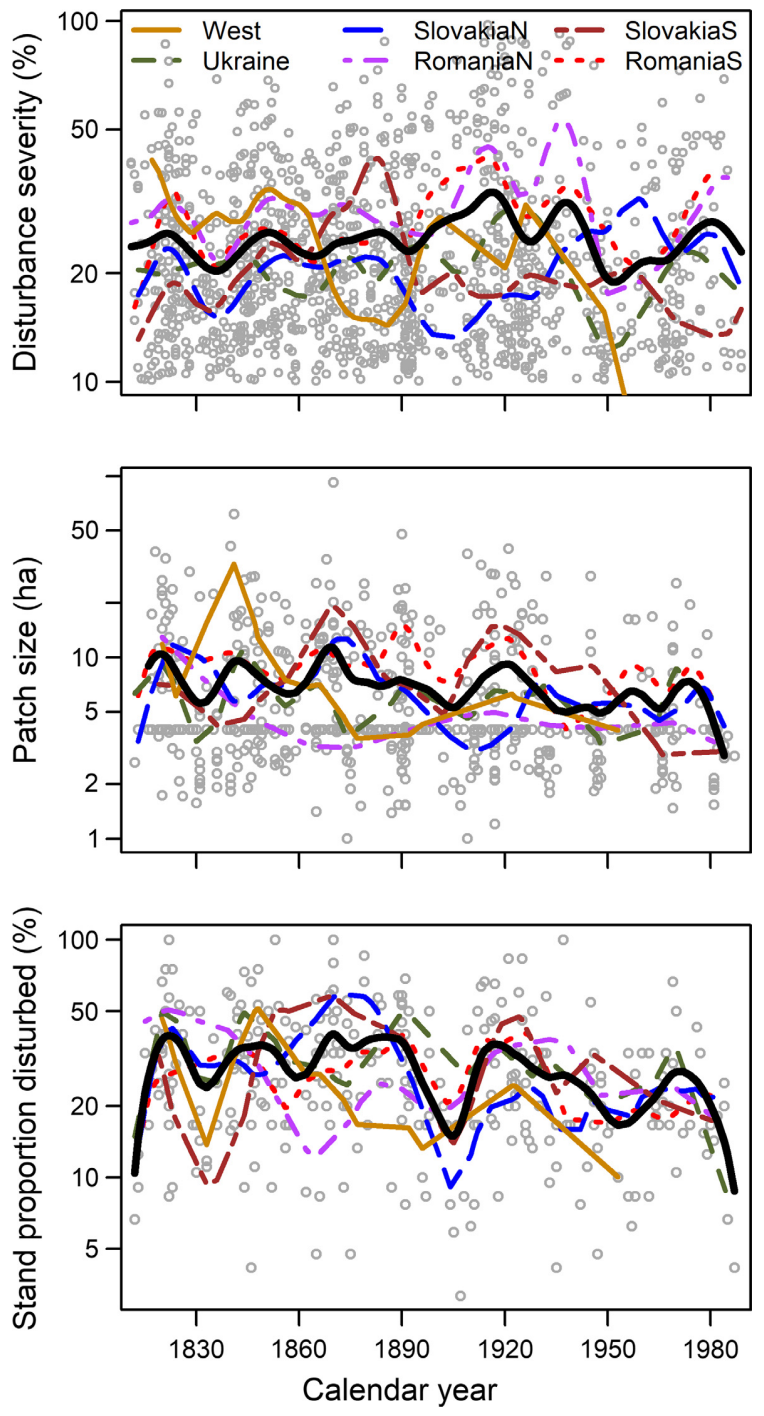

FIG. 4. Temporal trends in characteristics of disturbance events (dots), including plot-level severities (i.e., proportions of canopy areas disturbed), stand-level patch sizes, and stand proportion disturbed, smoothed using spline functions for each of the six subregions (colored lines) and for the entire region (black line).

using a kernel density function, we overcame the issue of arbitrary decadal binning, which often leads to overestimation of the number of disturbance events and underestimation their severity (Appendix S1: Fig. S7). The method also provides an effective means to separate signal from noise (i.e., the additional variability unrelated to disturbances) in disturbance chronologies by accentuating synchronous evidence exceeding a defined threshold (Fraver and White 2005, Trotsiuk et al. 2018).

The method allowed us to analyze the data at the level of individual disturbance events, which is, for example, helpful for the analyses of disturbance synchrony because in forests affected by a mixed-severity disturbance regime, individual plots are often affected by several disturbance events, and each event can span different subsets of plots (see an example in Appendix S1: Fig. S5). Previous approaches to evaluating disturbance histories (e.g., as presented in Schurman et al. 2018) estimated just aggregated decadal disturbance rate, thus they could not identify whether trends in disturbance chronologies resulted from changes in the mean disturbance severity or changes in the number of affected plots. We demonstrated that the observed decline in disturbance rates in our forests during the 20th century (Schurman et al. 2018) was more strongly driven by a decrease in the total area disturbed rather than a decrease in disturbance severity or patch size (Fig. 4). We believe that this and similar techniques could extend the utility of dendrochronological methods to estimate the historical range of variability of forest conditions, increase our understanding of moderateseverity disturbances, and provide valuable quantitative data that are currently lacking for managers attempting to emulate natural disturbance (Keane et al. 2009).

\section{Comparison of past and contemporary disturbances}

Our results can add to discussions concerning the presence or the extent to which natural disturbances have intensified, especially in an effort to discover the relative effects of climate change. The maximum patch sizes that we estimated across our sites were similar to the area-weighted mean patch sizes of contemporary natural disturbance events in similar mountain forests of Central Europe (Harz in Germany, 58 ha, and the High Tatras in northern Slovakia, $60 \mathrm{ha}$ ) analysed using satellite imagery (Senf and Seidl 2018). However, the recent disturbance in the Bohemian Forest mountain range was much larger (3,550 ha; Senf and Seidl 2018). The larger size of the recent disturbance is likely a result of several coincident factors, including the large-scale

TABLE 1. MANOVA model results showing the effects of subregion and time period on disturbance severity, patch size, and stand proportion.

\begin{tabular}{|c|c|c|c|c|c|c|c|c|c|c|c|c|c|c|c|}
\hline \multirow[b]{2}{*}{ Effect } & \multicolumn{4}{|c|}{ Subregion } & \multicolumn{4}{|c|}{ Period } & \multicolumn{4}{|c|}{ Subregion $\times$ Period } & \multirow{2}{*}{$\underset{r^{2}}{\text { Multiple }}$} & \multirow[b]{2}{*}{$P$} & \multirow{2}{*}{$\begin{array}{c}\text { Error } \\
\mathrm{df}\end{array}$} \\
\hline & $\mathrm{df}$ & $F$ & $r^{2}$ & $P$ & $\mathrm{df}$ & $F$ & $r^{2}$ & $P$ & $\overline{\mathrm{Df}}$ & $F$ & $r^{2}$ & $P$ & & & \\
\hline Severity & 5 & 4.41 & 0.07 & $<0.001$ & & & & & & & & & 0.07 & $<0.001$ & 295 \\
\hline Patch size & 5 & 2.16 & 0.04 & 0.059 & & & & & & & & & 0.04 & 0.059 & 295 \\
\hline $\begin{array}{l}\text { Stand } \\
\text { proportion }\end{array}$ & 5 & 0.32 & $<0.01$ & 0.901 & 5 & 3.92 & 0.06 & 0.002 & 24 & 1.58 & 0.12 & 0.045 & 0.18 & 0.009 & 266 \\
\hline
\end{tabular}


synchronization of forest ageing (in relation to the disturbance and management history), possibly combined with climate change-driven increases in sensitivity to disturbances (Čada et al. 2016). However, our areaweighted mean patch size of 16.4 ha was lower than that of contemporary disturbance events (Senf and Seidl 2018), likely because our analysis was more sensitive to small-scale, low-severity disturbance (i.e., it included events affecting few trees covering small areas) over a much longer history. Our results suggest that moderateand small-scale events prevailed in the history of the study forests, while the rotation period of events killing all trees over areas larger than 100 ha was considerably long. The potential of our data to study such large events is, however, limited (see Results and Appendix S1: Fig. S6). Generally, our approach provides the largely missing, rigorous, and long-term data that should be used to put characteristics of current disturbance into context (Schurman et al. 2018).

\section{Moderate disturbances and variation}

Moderate-severity and moderate-scale disturbances, described as events of $25-75 \%$ severity, with $25-75 \%$ stand proportion disturbed, and patch sizes of 10100 ha, were responsible for more than one-half of the total area disturbed across studied mountain spruce forests. They likely play a dominant role in many temperate and boreal forests because they affect a large aggregate area, where they fundamentally modulate the forest structure and its associated functions (Stueve et al. 2011). Moderate disturbances are probably particularly important in systems driven by wind and insect disturbances (Fraver et al. 2009). Their impact is often patchy and spatially variable, even though they can affect large areas (Kulakowski et al. 2017). As shown in our study, a single disturbance event often creates several discrete patches (of irregular shape) within a stand, and the severity can be highly variable within a single patch (see also Nagel et al. 2017). Studies of contemporary moderate disturbances support these results and suggest that these events introduce heterogeneity at small, but also moderate stand scales, and they generate important live and dead biological legacies, while usually maintaining stand resistance, resilience, biodiversity, and late-successional species composition by favoring advanced regeneration (Stueve et al. 2011, Meigs and Keeton 2018). The stand heterogeneity that developed as a result of these events and their frequent occurrence suggests that moderate disturbances are the key to the creation and maintenance of forest structural complexity over time rather than a linear development path without any disturbance events (Čada et al. 2016, Meigs et al. 2017).

A nonrandom spatial distribution of disturbance events seems to be a characteristic of moderate-scale wind and bark-beetle disturbances. The spatial autocorrelation may be partially attributable to higher intensity of these disturbances that result in the mortality of larger groups of trees and disturbance patches. However, wind and bark-beetle (Ips typographus) disturbances are modulated by tree and stand sensitivity, topography, and climate (Thom et al. 2013); all of these factors can contribute to disturbance spatial autocorrelation. Furthermore, individual disturbance events can generate favorable conditions (such as exposed or injured trees) for subsequent disturbance events, so that consecutive disturbance events are more likely to occur nearby (Thom et al. 2013). These relationships can synchronize stand dynamics over larger areas beyond the effects of individual events, as supported by our analysis of spatial autocorrelation. Synchronous aging of our study forests resulting from past nonequilibrium dynamics was recently described by Schurman et al. (2018). The magnitude to which the forest types are predisposed to nonequilibrium dynamics and synchronous aging beyond the effects of individual disturbance events may also be related to site, climatic conditions, and disturbance drivers. For example, exposed, high-altitude spruce forests driven by bark-beetle outbreaks can be more sensitive to nonequilibrium dynamics, or, in other words, to higher temporal and spatial autocorrelation of disturbance events, than other forest types in Europe. We suggest that several levels of synchronization at different temporal scales could be observed in forest dynamics. There is evidence of an annual scale synchronization driven, for example, by climatic factors (Senf and Seidl 2018), but also evidence of decadal or centennial scales of synchronization that could be driven in some forest types, for example, by aging (Schurman et al. 2018).

The variation of disturbance characteristics is expected to be related to disturbance drivers, topography, site conditions, or geographical position, which are the factors that vary regionally. Our study forests are expected to be exposed to increased frequency or size of disturbances because of exposed topographic positions at high elevations or because of insect disturbances (Fraver et al. 2009), which are moreover often coupled with windthrow events (Senf and Seidl 2018). In contrast, steep slopes, complex topography, and poor site conditions of most of our study sites can contribute to more limited disturbance severity or size compared to spruce forests on flatter terrain or mountain ridges (Trotsiuk et al. 2014, Čada et al. 2016, Senf and Seidl 2018). Nevertheless, the variation in disturbance characteristics across subregions and over time, as explained by our models, were not notably beyond the general variation of disturbance characteristics. This finding implies that the region-wide trends are generally applicable until a more detailed understanding of the relationship between disturbance characteristics and environmental conditions that affect them more directly is available. We suggest that the nonequilibrium nature of forest disturbances causing meaningful temporal and spatial variation should be considered during management application and mean trends of rotation periods of the 
disturbance characteristics (Fig. 2) should be coupled with an understanding of their range of variation. Such an approach also allows for some flexibility for decision makers to use a range of options to achieve the desired ecosystem services.

\section{Management implications}

Current forest management approaches in Central and Eastern European forests typically generate a much narrower range of structural variation than occurs in natural forests. Using homogeneous techniques, current approaches, for example, create either a combination of highly opened and shaded light conditions in even-aged systems, or homogeneously shaded conditions produced when selection cuttings are applied under continuous cover forestry systems. These conditions differ from the complex light conditions observed in natural forests after moderate-severity disturbances (Meigs and Keeton 2018). Our results support a similar conclusion by revealing that current management treatments tend to be extremely severe and relatively small, and their rotation periods are much shorter compared to the natural disturbance spectrum. Thus, current management practices are, in many important ways, outside the range of variation observed in natural forests (Fig. 2). Shorter rotation periods in managed forests clearly shift age distributions towards younger forests, thus the presence of old trees and related late developmental structures are typically absent in managed forests. Prevailing management often fails to consider the biological legacies of natural disturbance and tree senescence (Meigs and Keeton 2018), thus the related structures, such as dead and dying trees or lying deadwood, are missing. Our quantitative results could be used to guide efforts to emulate natural disturbance patterns in logging operations (Keane et al. 2009, Long 2009) and to provide more exact recommendations for retention forestry approaches (Fedrowitz et al. 2014, Mori and Kitagawa 2014).

Ecological benefits would be maximized where forest management acknowledges the broad spectrum of natural disturbance effects and their biological legacies. Heterogeneous treatments should be preferred to mimic the observed spectrum of low- to moderate-severity and small- to moderate-size disturbances, and they should be distributed spatially and temporally in accordance with natural patterns to increase landscape connectivity and forest resilience. The severity of treatments should be significantly lower than $100 \%$. Some portion of the trees and important structural attributes should be retained in the stand perpetually to facilitate key structural elements (including deadwood) and stand resilience. The level of retention should consider the need for structural legacy amounts, the cumulative effects of natural and human disturbances, landscape structure resulting from the prevailing management system, and historical disturbance rates. For European mountain forests, based on the ninety-eighth percentile of historical natural disturbance severities, we recommend that the amount of retained trees would represent at least $30 \%$ of the canopy area. Combining appropriate levels of retention with spatially irregular treatment shapes and severities could, in accordance with natural disturbance patch sizes, enable the application of treatments to larger, moderate-scale areas than are typically considered under current approaches (Meigs and Keeton 2018). The eighty-seventh percentile of our patch sizes would, for example, correspond to the maximum treatment size of about 15 ha. Retention should include patches without any logging operations and some degree of natural disturbances should also be accepted in managed areas to maintain the associated legacy structures and promote their accumulation across the landscape. The probable natural mortality of a portion of the retained trees would be consistent with the positive effects of natural disturbances on biodiversity (Lehnert et al. 2013).

Our estimations of disturbance characteristics could also be used to help design forest conservation areas that are key for maintaining diversity. These areas should be large enough and adequately connected to guarantee forest resilience to disturbances. Effective conservation requires protection of a "minimum dynamic area" that can be estimated, for instance, using the characteristics of natural disturbances; the protected area should be considerably larger than the largest disturbance patch and include different tree age cohorts (Pickett and Thompson 1978). Based on this suggestion, our analyses support a minimum reserve area on the order of hundreds of hectares. However, where stands are geographically isolated (far from other reserves or surrounded by a hostile environment) or structurally homogeneous (in terms of tree age structure), much larger reserves (possibly larger than 10,000 ha) could be required to guarantee viable populations of species under the moderatescale, mixed-severity disturbance regime (Lehnert et al. 2013, Mikoláš et al. 2017a).

\section{Conclusions}

We tested a comprehensive method of estimating past disturbance severity, patch size, and stand proportion disturbed using a dendrochronological reconstruction across an extensive plot network in remaining fragments of European primary forests; this approach can provide valuable baseline data for ecological research and contemporary forest landscape management. Our evaluation emphasized the significance of moderate-scale, moderate-severity, disturbance events for dynamics and management of temperate forests, particularly those driven by wind and insect disturbances. Moderate disturbances, often overlooked in past research, were especially common when comparing the total area they affected to that of small- and large-scale events. Natural disturbances should be considered a significant process that creates conditions consistent with native species 
habitat requirements. Therefore, to sustain biodiversity and ecosystem functions, forest management efforts (strict reserves network and the sustainable forest management elsewhere) should be based on the historical range of forest variability (e.g., the variation of disturbance severities and sizes) and key structural elements (e.g., patches of living trees, advanced regeneration, dead standing trees, lying deadwood) should be maintained. Our quantitative estimates of disturbance characteristics provide rigorous data to guide such efforts.

\section{ACKNOWLEDGMENTS}

We thank the numerous local experts and managers for their help and permissions with the field work. We thank the numerous technicians that helped to collect the data. Input from anonymous reviewers greatly improved the manuscript. Funding for this research was provided by the Czech Science Foundation (Grant GACR no. 16-23183Y) and the Czech Ministry of Education, Youth and Sports (project Inter-Transfer no. LTT20016 and project EVA4.0 no. CZ.02.1.01/0.0/0.0/16_019/ 0000803).

\section{Literature Cited}

Achat, D. L., C. Deleuze, G. Landmann, N. Pousse, J. Ranger, and L. Augusto. 2015. Quantifying consequences of removing harvesting residues on forest soils and tree growth - a metaanalysis. Forest Ecology and Management 348:124-141.

Betts, M. G., et al. 2019. Extinction filters mediate the global effects of habitat fragmentation on animals. Science $366: 1236-1239$.

Bjørnstad, O. N. 2018. ncf: spatial covariance functions. R package version 1.2-5. https://cran.r-project.org/package $=$ ncf

Brang, P., et al. 2014. Suitability of close-to-nature silviculture for adapting temperate European forests to climate change. Forestry 87:492-503.

Čada, V., R. C. Morrissey, Z. Michalová, R. Bače, P. Janda, and M. Svoboda. 2016. Frequent severe natural disturbances and non-equilibrium landscape dynamics shaped the mountain spruce forest in central Europe. Forest Ecology and Management 363:169-178.

Cardellini, G., et al. 2018. EFO-LCI: A New Life Cycle Inventory database of forestry operations in Europe. Environmental Management 61:1031-1047.

Drapeau, P., M. A. Villard, A. Leduc, and S. J. Hannon. 2016. Natural disturbance regimes as templates for the response of bird species assemblages to contemporary forest management. Diversity and Distributions 22:385-399.

Duong, T. 2007. ks: Kernel density estimation and kernel discriminant analysis for multivariate data in R. Journal of Statistical Software 21:1-16.

Fedrowitz, K., et al. 2014. Can retention forestry help conserve biodiversity? A meta-analysis. Journal of Applied Ecology 51:1669-1679.

Fraver, S., and A. S. White. 2005. Identifying growth releases in dendrochronological studies of forest disturbance. Canadian Journal of Forest Research 35:1648-1656.

Fraver, S., A. S. White, and R. S. Seymour. 2009. Natural disturbance in an old-growth landscape of northern Maine, USA. Journal of Ecology 97:289-298.

Janda, P., et al. 2017. The historical disturbance regime of mountain Norway spruce forests in the Western Carpathians and its influence on current forest structure and composition. Forest Ecology and Management 388:67-78.
Keane, R. E., P. F. Hessburg, P. B. Landres, and F. J. Swanson. 2009. The use of historical range and variability (HRV) in landscape management. Forest Ecology and Management 258:1025-1037.

Kraus, D., and F. Krumm, editors. 2013. Integrative approaches as an opportunity for the conservation of forest biodiversity. European Forest Institute, Joensuu, Finland.

Kulakowski, D., et al. 2017. A walk on the wild side: Disturbance dynamics and the conservation and management of European mountain forest ecosystems. Forest Ecology and Management 388:120-131.

Lehnert, L. W., C. Bässler, R. Brandl, P. J. Burton, and J. Müller. 2013. Conservation value of forests attacked by bark beetles: Highest number of indicator species is found in early successional stages. Journal for Nature Conservation 21:97-104.

Long, J. N. 2009. Emulating natural disturbance regimes as a basis for forest management: a North American view. Forest Ecology and Management 257:1868-1873.

Lorimer, C. G., and L. E. Frelich. 1989. A methodology for estimating canopy disturbance frequency and intensity in dense temperate forests. Canadian Journal of Forest Research 19:651-663.

Marini, L., et al. 2017. Climate drivers of bark beetle outbreak dynamics in Norway spruce forests. Ecography 40:1426-1435.

Meigs, G. W., et al. 2017. More ways than one: mixed-severity disturbance regimes foster structural complexity via multiple developmental pathways. Forest Ecology and Management 406:410-426.

Meigs, G. W., and W. S. Keeton. 2018. Intermediate-severity wind disturbance in mature temperate forests: legacy structure, carbon storage, and stand dynamics. Ecological Applications 28:798-815.

Meyer, P., et al. 2017. A matter of time: self-regulated tree regeneration in a natural Norway spruce (Picea abies) forest at Mt. Brocken, Germany. European Journal of Forest Research 136:907-921.

Mikoláš, M., et al. 2017a. Mixed-severity natural disturbances promote the occurrence of an endangered umbrella species in primary forests. Forest Ecology and Management 405:210-218.

Mikoláš, M., M. Tejkal, T. Kuemmerle, P. Griffiths, M. Svoboda, T. Hlásny, P. J. Leitão, and R. C. Morrissey. 2017b. Forest management impacts on capercaillie (Tetrao urogallus) habitat distribution and connectivity in the Carpathians. Landscape Ecology 32:163-179.

Mikoláš, M., et al. 2019. Primary forest distribution and representation in a Central European landscape: results of a largescale field-based census. Forest Ecology and Management 449:117466.

Mori, A. S., and R. Kitagawa. 2014. Retention forestry as a major paradigm for safeguarding forest biodiversity in productive landscapes: a global meta-analysis. Biological Conservation 175:65-73.

Nagel, T. A., S. Mikac, M. Dolinar, M. Klopcic, S. Keren, M. Svoboda, J. Diaci, A. Boncina, and V. Paulic. 2017. The natural disturbance regime in forests of the Dinaric Mountains: a synthesis of evidence. Forest Ecology and Management 388:29-42.

Pickett, S. T. A., and J. N. Thompson. 1978. Patch dynamics and the design of nature reserves. Biological Conservation 13:27-37.

R Core Team. 2018. R: a language and environment for statistical computing. R Foundation for Statistical Computing, Vienna, Austria. www.R-project.org

Šamonil, P., L. Kotík, and I. Vašíčková. 2015. Uncertainty in detecting the disturbance history of forest ecosystems using dendrochronology. Dendrochronologia 35:51-61. 
Schurman, J. S., et al. 2018. Large-scale disturbance legacies and the climate sensitivity of primary Picea abies forests. Global Change Biology 24:2169-2181.

Senf, C., and R. Seidl. 2018. Natural disturbances are spatially diverse but temporally synchronized across temperate forest landscapes in Europe. Global Change Biology 24:1201-1211.

Seymour, R. S., A. S. White, and P. G. DeMaynadier. 2002. Natural disturbance regimes in northeastern North Americaevaluating silvicultural systems using natural scales and frequencies. Forest Ecology and Management 155:357-367.

Stueve, K. M., C. H. Hobie Perry, M. D. Nelson, S. P. Healey, A. D. Hill, G. G. Moisen, W. B. Cohen, D. D. Gormanson, and C. Huang. 2011. Ecological importance of intermediate windstorms rivals large, infrequent disturbances in the northern Great Lakes. Ecosphere 2:art2.

Svoboda, M., et al. 2014. Landscape-level variability in historical disturbance in primary Picea abies mountain forests of the Eastern Carpathians, Romania. Journal of Vegetation Science 25:386-401.

Thom, D., R. Seidl, G. Steyrer, H. Krehan, and H. Formayer. 2013. Slow and fast drivers of the natural disturbance regime in Central European forest ecosystems. Forest Ecology and Management 307:293-302.

Trotsiuk, V., N. Pederson, D. L. Druckenbrod, D. A. Orwig, D. A. Bishop, A. Barker-Plotkin, S. Fraver, and D. Martin-Benito. 2018. Testing the efficacy of tree-ring methods for detecting past disturbances. Forest Ecology and Management 425:59-67.

Trotsiuk, V., M. Svoboda, P. Janda, M. Mikolas, R. Bace, J. Rejzek, P. Samonil, O. Chaskovskyy, M. Korol, and S. Myklush. 2014. A mixed severity disturbance regime in the primary Picea abies (L.) Karst. forests of the Ukrainian Carpathians. Forest Ecology and Management 334: 144-153.

Valtera, M., P. Šamonil, and K. Boublík. 2013. Soil variability in naturally disturbed Norway spruce forests in the Carpathians: Bridging spatial scales. Forest Ecology and Management 15:134-146.

Wermelinger, B. 2004. Ecology and management of the spruce bark beetle Ips typographus - a review of recent research. Forest Ecology and Management 202:67-82.

\section{SUPPORTING INFORMATION}

Additional supporting information may be found online at: http://onlinelibrary.wiley.com/doi/10.1002/eap.2189/full

\section{Data Availability}

Data are available from the Dryad Digital Repository: https://doi.org/10.5061/dryad.08kprr507 